\title{
RECICLAGEM E REUTILIZAÇÃO DE RESÍDUOS: UM PROJETO SOCIOAMBIENTAL DESENVOLVIDO NA EDUCAÇÃO DE JOVENS E ADULTOS (EJA) DO SESC SANTO AMARO, RECIFE (PE)
}

\author{
Angela Cristina Pascaretta Gallo ${ }^{1}$ \\ Mariana Guenther ${ }^{2}$
}

Resumo: A geração e acúmulo de resíduos sólidos nos centros urbanos têm sido um dos maiores problemas ambientais da atualidade, e a educação para a sustentabilidade se configura como uma solução viável e efetiva. A Educação Ambiental é condição fundamental para a formação do futuro cidadão e deve ser inserida sistematicamente nos projetos político-pedagógicos das escolas. O projeto apresentado aqui teve início em sala de aula, com as turmas de $3^{\underline{a}}$ e $4^{\underline{a}}$ fases da Educação de Jovens e Adultos (EJA) do Serviço Social do Comércio (SESC) na unidade executiva de Santo Amaro (Recife - PE). Expandindo-se através de outros setores da unidade e comunidade vizinha, tornou-se um projeto socioambiental de referência para outras unidades do SESC. Esse projeto, iniciado em 2009, incluiu uma série de ações socioambientais: coleta seletiva dentro da unidade e encaminhamento para a reciclagem através de uma cooperativa de catadores da comunidade; produção de artesanatos com o material não rentável para venda direta em uma ação de capacitação e ressocialização em presídios masculinos; transformação do óleo utilizado na cantina em sabão e posterior venda do mesmo pelos moradores da comunidade do entorno; e compostagem dos resíduos orgânicos para produção de húmus. Todas essas ações envolveram alunos e funcionários da unidade SESC Santo Amaro bem como a comunidade do entorno. O objetivo deste relato é difundir nossa experiência de sucesso para o grande público para que sirva de inspiração para futuros projetos desse porte em várias cidades brasileiras, para que o "lixo" deixe de ser visto como um problema e se transforme em uma solução socioambiental.

Palavras-chave: Educação Ambiental, Resíduos sólidos, Sustentabilidade, Poluição.

1SESC Santo Amaro. E-mail: angelacpgallo@gmail.com

2Instituto de Ciências Biológicas, Universidade de Pernambuco. E-mail: mariana.guenther@upe.br

Revbea, São Paulo, V. 10, № 4: 11-23, 2015.

revista brasileira

educação ambiental 


\section{Introdução}

A geração e acúmulo de resíduos sólidos nos centros urbanos têm sido um dos maiores problemas ambientais da atualidade. E a principal solução para esse problema está na educação para a sustentabilidade, ou seja, trabalhar o consumo consciente levando em consideração a política dos "3Rs", reduzindo o consumo, reutilizando os resíduos e fazendo a coleta seletiva para ser encaminhada para as indústrias de reciclagens (GRIPPI, 2006; PEDRINI, 2008).

A Educação Ambiental é condição fundamental para a formação do futuro cidadão, cabendo a nós, professores, capacitar os alunos incluindo em nossos planejamentos, conteúdos que abordem problemas e soluções socioambientais. Tratar destas questões significa orientar o aprendente a usar de forma consciente os recursos naturais, garantindo desta forma a qualidade de vida para a sociedade atual e a das futuras gerações. (BOFF, 2013; DIAS, 2009).

Isto só será possível se inserirmos sistematicamente a Educação Ambiental nos projetos político-pedagógicos das escolas desde a educação infantil. A conscientização ambiental deve ser trabalhada com os alunos desde a mais tenra infância, como forma de inserir nos seus hábitos diários comportamentais as práticas ambientalmente corretas. Aos primeiros contatos da vida escolar, o aluno precisa reconhecer-se como parte dependente de seu habitat. Deve entender que é do meio ambiente que ele retira tudo o que precisa para sua sobrevivência, e é por isto que se deve tratar com respeito os recursos naturais (CASCINO, 1999; MORAES; MANCUSO, 2004; PENTEADO, 2000).

Este projeto teve início em sala de aula, com as turmas de $3^{\text {a }}$ e $4^{\underline{a}}$ fases da Educação de Jovens e Adultos (EJA) do Serviço Social do Comércio (SESC) na unidade executiva de Santo Amaro (Recife - PE). Durante as aulas de Ciências, no momento em que trabalhávamos os conteúdos programáticos relacionados à conservação dos recursos naturais renováveis e não renováveis existentes no planeta, surgiram vários questionamentos sobre o nosso papel (alunos, professores e funcionários) dentro de um contexto mais local, ou seja, dentro da escola.

Um dos questionamentos foi relacionado aos coletores de resíduos recicláveis existentes na entrada da escola: apesar dos mesmos servirem à prática da coleta seletiva, os alunos observaram, por diversas vezes, os funcionários da limpeza misturarem tudo no momento do descarte. O mesmo foi discutido em relação ao descarte dos resíduos coletados nas residências de alguns alunos, que disseram ter observado acontecer o mesmo quando o caminhão da limpeza urbana passava: novamente tudo era misturado. 
A partir destas discussões, e baseados na ideia de que todos somos parte integrante e responsável pelo ambiente em que vivemos, resolvemos desenvolver um projeto que teve como ponto de partida a destinação correta dos resíduos descartados pela escola, mas foi com o tempo ganhando mais força e parceiros e tornando-se um projeto socioambiental de referência para outras Unidades. Assim sendo, pretendemos através deste trabalho abrir portas para que futuras pesquisas possam ser agregadas e que novas experiências venham contribuir para que o "lixo" deixe de ser um problema para se transformar em uma solução socioambiental.

\section{Metodologia}

A comunidade onde foi desenvolvido esse projeto está situada no

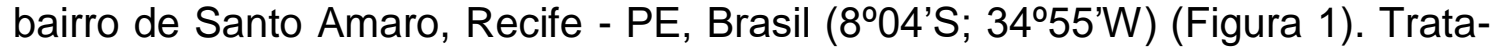
se de uma área extremamente carente, onde existe uma comunidade de baixa renda que vive da coleta e venda de resíduos recicláveis.

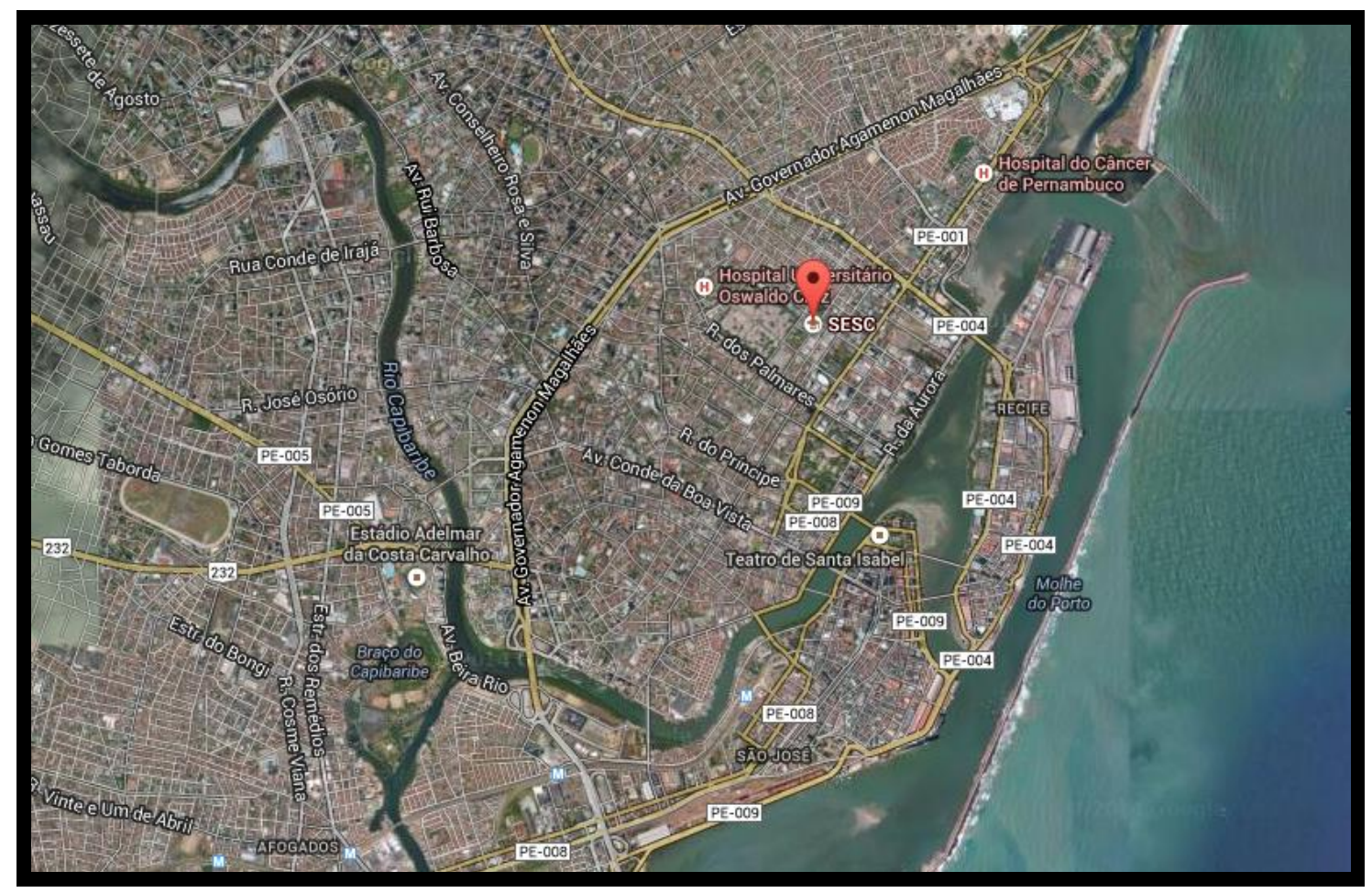

Figura 1: Localização da área de estudo. Fonte: Google Maps.

Este projeto teve início no ano de 2009, em sala de aula, com as turmas de $3^{\mathrm{a}}$ e $4^{\mathrm{a}}$ fases da Educação de Jovens e Adultos do Serviço Social do Comércio (SESC) na unidade executiva de Santo Amaro, e se deu em várias etapas descritas detalhadamente a seguir. 


\section{Levantamento/reconhecimento do problema a ser trabalhado}

A primeira etapa do projeto consistiu em um levantamento qualitativo dos resíduos que eram descartados na unidade de Santo Amaro, primeiramente nas salas de aula da EJA e entorno, e posteriormente nos demais departamentos do SESC: a Central de Atendimentos, a Gerência, a Seção de Trabalho com Grupos, a Biblioteca, a Educação Infantil e Fundamental do Ensino Regular, e as Seções de Esporte e Cultura.

\section{Planejamento e implementação da coleta seletiva}

Após realizado o levantamento do material descartado implementamos a coleta seletiva nas salas de aula da Educação de Jovens e Adultos. Foram instalados inicialmente 02 coletores em cada uma das 04 salas de aula de EJA onde funcionavam, na época, dois turnos (manhã e noite). Os coletores foram devidamente etiquetados, sendo um com "Resíduos Sólidos" e o outro com "Lixo Comum". Durante este processo os demais alunos foram orientados pelos alunos e professores participantes deste projeto no procedimento correto de descarte dos resíduos.

\section{Busca de parcerias para a destinação correta dos resíduos}

A coleta seletiva não garante a destinação final adequada dos mesmos. Sendo assim fomos à busca de parcerias. O Espaço Cultural Santo Amaro, onde funciona uma OSCIP (Organização da Sociedade Civil de Interesses Públicos), acolhe um grupo de catadores, que vivem da coleta seletiva de resíduos recicláveis. Assim foi formada a parceria.

\section{Expansão da coleta seletiva aos demais setores do SESC}

Com a implementação da coleta seletiva nas salas de aula do EJA e a garantia do descarte adequado junto aos catadores associados à OSCIP do Espaço Cultural Santo Amaro, foi possível a expansão do projeto para os diversos setores da Unidade. Assim, foram contemplados: a Central de Atendimentos, a Gerência, a Seção de Trabalho com Grupos, a Biblioteca, a Educação Infantil e Fundamental do Ensino Regular, e as Seções de Esporte e Cultura.

Nesta etapa, os funcionários de cada setor foram devidamente orientados pelos alunos e professores da EJA quanto ao descarte correto dos resíduos, cuidando para que os mesmos estivessem secos e limpos. Desse modo, multiplicamos os esforços e a conscientização da importância da reciclagem. 


\section{Gestão de outros tipos de resíduos gerados nesta Unidade}

Depois de estabelecida e solidificada a coleta seletiva e destinação correta dos resíduos sólidos em toda a Unidade do SESC Santo Amaro, passamos a focar em outros resíduos gerados na Unidade, como o óleo utilizado no preparo das refeições e lanches, ora despejados na pia, e os resíduos de alimento.

\section{Resultados e Discussão}

\section{Levantamento dos resíduos descartados na Unidade Santo Amaro do Sesc}

Os principais resíduos descartados em sala de aula são: papel e papelão, embalagens plásticas, metais (latas) e material orgânico. Tonners de impressora e lâmpadas também são descartados nesse setor. Incluindo os demais setores da Unidade foram encontrados outros tipos de resíduos, como recipientes de vidro (garrafas) e óleo de cozinha na Cantina.

\section{Implementação da coleta seletiva nas salas de aula}

De posse da informação dos principais itens descartados foram eleitas 4 categorias de separação: papel e papelão, vidro, plástico e alumínio. Os resíduos sólidos foram então recolhidos em dias determinados e a quantidade descartada acompanhada pela equipe do projeto (coordenadora e alunos). Ao final de cada mês os resultados dessa ação foram avaliados pela equipe de Meio Ambiente do SESC.

Em pouco tempo depois da implementação do projeto já percebemos uma redução significativa dos resíduos depositados no lixo comum, e um aumento expressivo no montante de resíduos recicláveis coletados.

\section{Parceria com a comunidade para a destinação correta dos resíduos}

A parceria com a OSCIP do Espaço Cultural de Santo Amaro, situado no entorno do SESC foi, e continua sendo, extremamente frutífera, uma vez que lá já havia um grupo de mulheres que se dedicam à venda de resíduos sólidos recicláveis.

Os resíduos coletados (papel e papelão, vidro, plástico e alumínio) são doados então à Associação de Catadoras que revendem parte desse material, gerando renda para o sustento de suas famílias (Figura 2). A quantidade de resíduos recolhida por mês nesta Unidade do SESC era acompanhada através do valor de revenda do mesmo pela Associação de Catadoras, assim foi possível estimar a captação de resíduos bem como o resultado dessa ação como geração de renda para a Associação. 


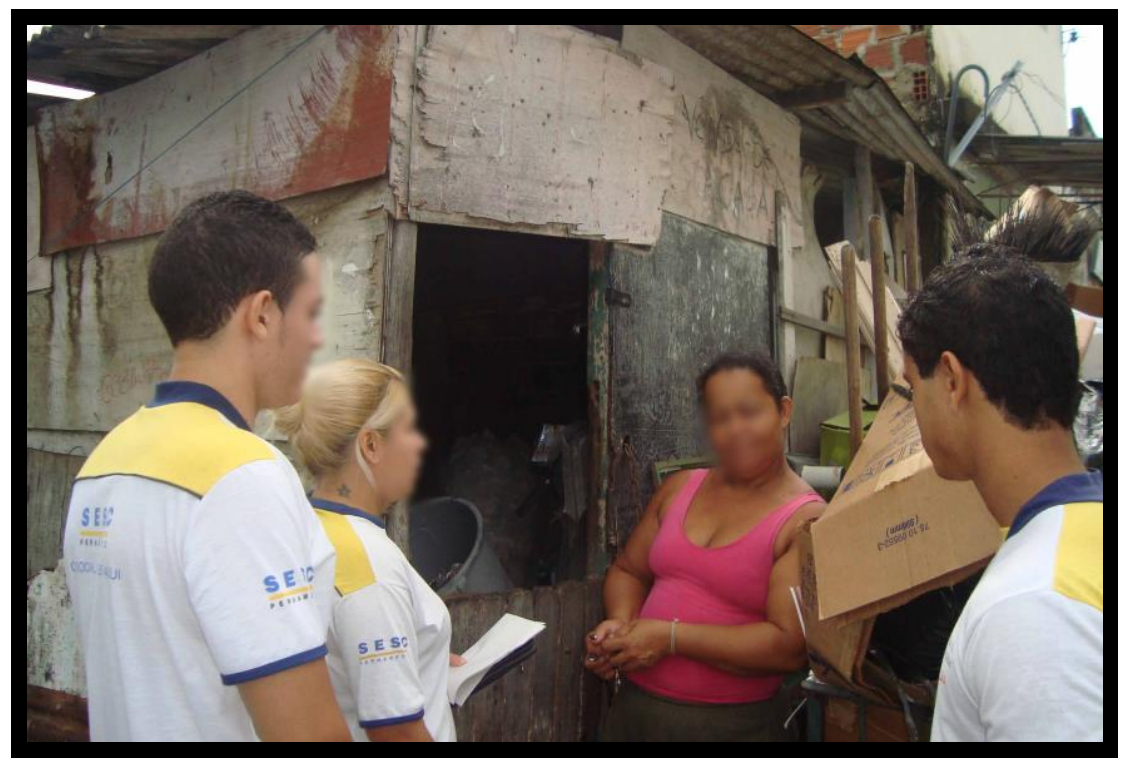

Figura 2: Visita dos alunos a OSCIP do bairro de Santo Amaro.

Parte desse material, que não é diretamente vendido, como embalagens de papel A4 e jornais, é utilizado para a confecção de produtos como bolsas, jogos-americanos, porta-lápis, porta-retratos, cestos de roupa, cesta para pães, luminárias, entre outros (Figura 3). Essa produção faz parte de um trabalho de ressocialização nos presídios masculinos, desenvolvido por uma das senhoras da comunidade. O objetivo é a capacitação dos apenados em atividades manuais que possam garantir seu sustento e sua inserção na sociedade, após o cumprimento da pena.

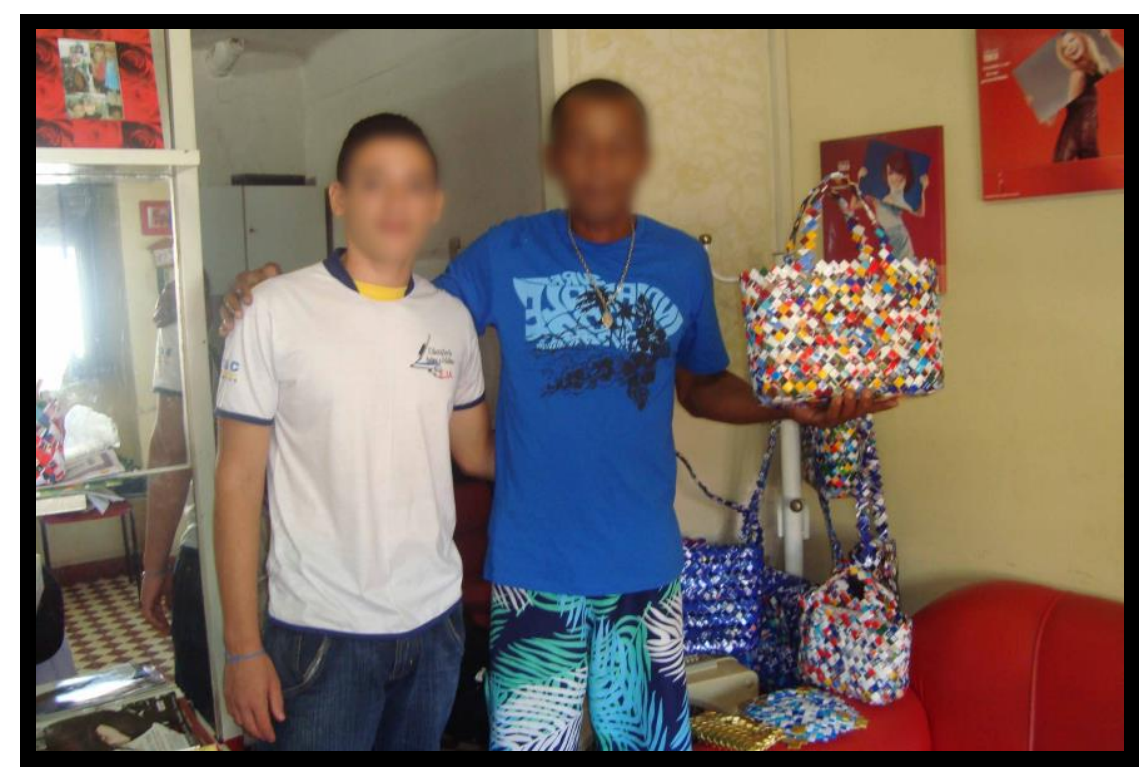

Figura 3: Artesanato feito a partir de material reciclável. 
Os alunos participaram ativamente desse processo, se inteirando da realidade de quem vive da prática da coleta seletiva, e se sensibilizando para a mudança de comportamento em relação aos resíduos descartados, tratando-os dessa maneira como matéria prima (quando separados), e não como lixo (quando misturados). Assim, puderam perceber que a coleta seletiva beneficia tanto o ambiente quanto as famílias que dependem dessa renda.

\section{Expansão da coleta seletiva aos demais setores do SESC (além da Unidade de ensino)}

A expansão da coleta seletiva aos demais setores do SESC foi extremamente positiva, tanto do ponto de vista do aumento da coleta de resíduos e geração de renda para a comunidade, quanto do engajamento dos funcionários de todos os setores da Unidade na mesma causa. A mudança de atitude em relação à disposição dos resíduos no trabalho também incitou uma mudança de atitude em suas residências, como relatado por muitos funcionários após a implantação deste projeto.

Ao final de cada semestre o projeto era reavaliado pela equipe executora (coordenadora e alunos), levantando-se os pontos positivos e os pontos a serem melhorados, através de observações comparativas entre antes e depois da implantação da coleta. A cada semestre letivo o projeto seguiu-se com o mesmo modelo angariando sempre novos alunos ingressantes nas turmas do EJA desta Unidade.

\section{Gestão de outros tipos de resíduos gerados nesta Unidade}

Dentre os demais resíduos gerados na Unidade do SESC, o óleo utilizado no preparo de lanches e refeições na Cantina e despejado diretamente na pia, contaminando o solo, o lençol freático e os mananciais que abastecem nossa cidade, era fruto de grande inquietação dos alunos participantes do projeto.

$\mathrm{Na}$ própria sala de aula, através de pesquisas e aulas práticas, conseguimos transformar o óleo utilizado na cantina em sabão. Aproveitando as aulas de química, trabalhamos os conteúdos referentes às reações químicas utilizando como ferramenta a transformação do óleo usado em sabão (receita a seguir).

Ingredientes:

- $5 \mathrm{~L}$ de óleo usado

- $1 \mathrm{~L}$ de água fervendo

- 1 copo (200 ml) de sabão em pó (qualquer marca)

- 4 colheres de sopa de essência (qualquer aroma)

- 900 g de soda cáustica em escamas. 


\section{Modo de fazer}

Em um balde de plástico, colocar o sabão em pó e a soda. Em seguida com muito cuidado e aos poucos, colocar a água fervendo e misturar até derreter as escamas da soda. Logo em seguida adicionar a esta mistura o óleo peneirado e a essência misturar o mesmo adquirir uma consistência mais grossa e depositar na forma de sua preferência. Alertamos também para o uso dos equipamentos de proteção individual (EPI) como: óculos, luvas e máscara ou proteção similar (Figura 4).

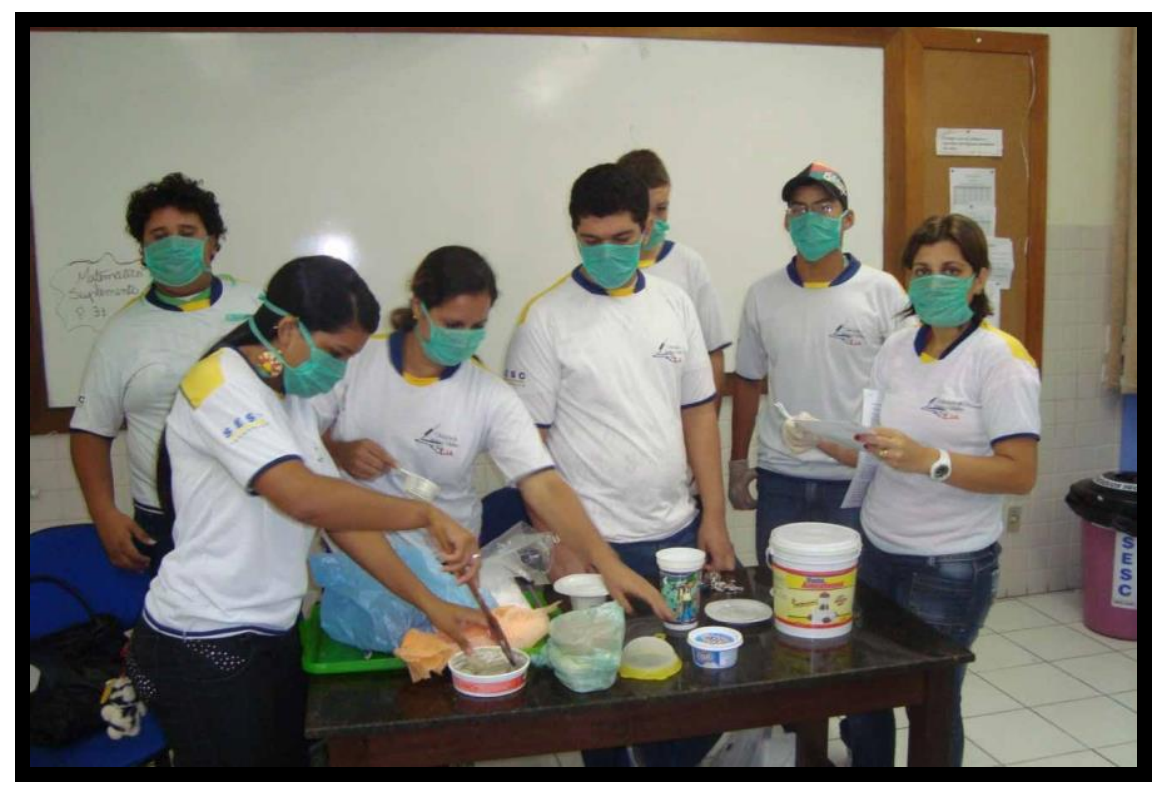

Figura 4: Aula prática de química: transformando o óleo usado em sabão.

Em seguida, essa prática foi repassada pelos alunos para alguns moradores da comunidade. Durante essa etapa foram discutidas as consequências desastrosas do óleo quando lançado no meio ambiente e a importância de sua reutilização como fonte de renda. Estes moradores da comunidade vêm produzindo sabão desde então, e vendem, a preço de mercado, com boa aceitação (Figura 5).

A oficina de transformação do óleo em sabão ainda hoje é ministrada várias vezes durante 0 ano, desde 2009, para funcionários e comunidade do entorno do SESC - Santo Amaro, nos constantes eventos promovidos durante o ano pelo Departamento de Trabalhos com Grupos. Tal oficina de sabão ganhou proporções inesperadas, e tem sido solicitada para realização durante as SIPATs (Semana Interna de Prevenção de Acidentes), promovida pelas CIPAs (Comissão Interna de Prevenção de Acidentes) de várias empresas Pernambucanas, sempre com a intenção de através da Educação Ambiental, sensibilizar o público para a prática da sustentabilidade. 


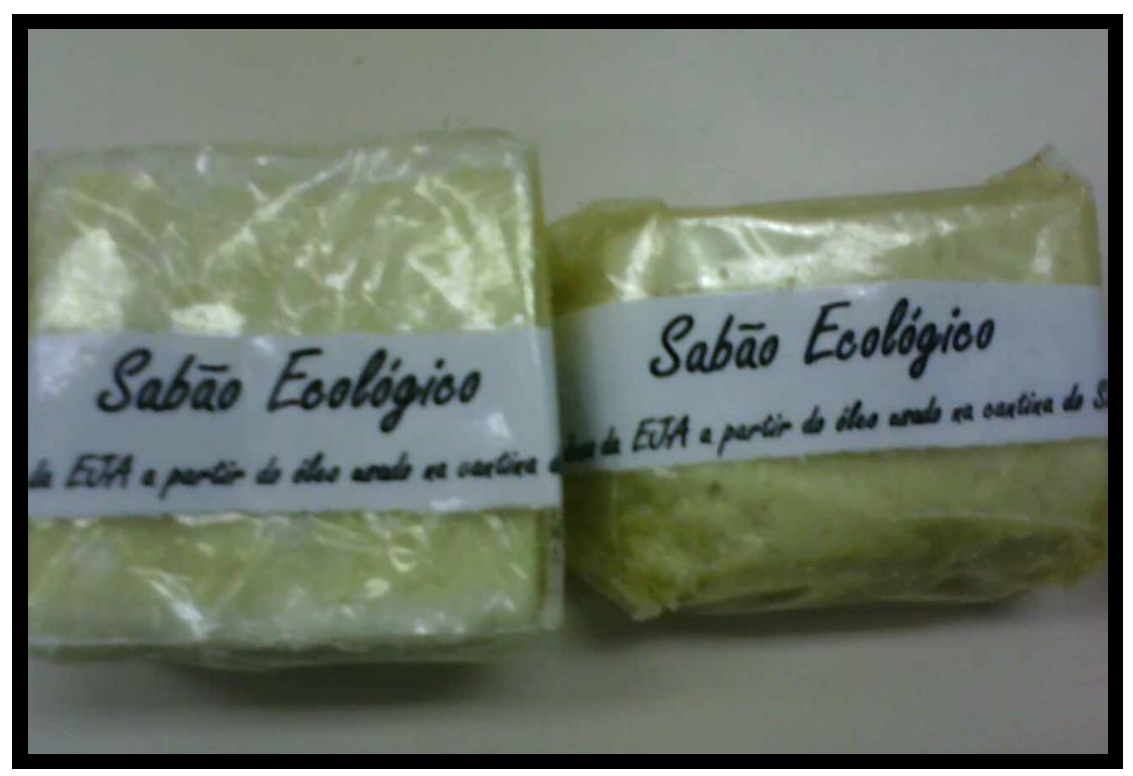

Figura 5: Sabão ecológico embalado para a venda.

Outra atividade, ainda em estudo, consiste na destinação correta dos restos de alimentos descartados pela cozinha, à produção de húmus ou de gás para cozimento dos alimentos, através da aquisição de um biodigestor. Nesta etapa a nossa intenção foi de demonstrar para o aluno que os restos de resíduos orgânicos poderiam ser transformados através de sua decomposição pelos fungos e bactérias em dois subprodutos: gás e fertilizante, ou serem transformados em húmus (Figura 6).

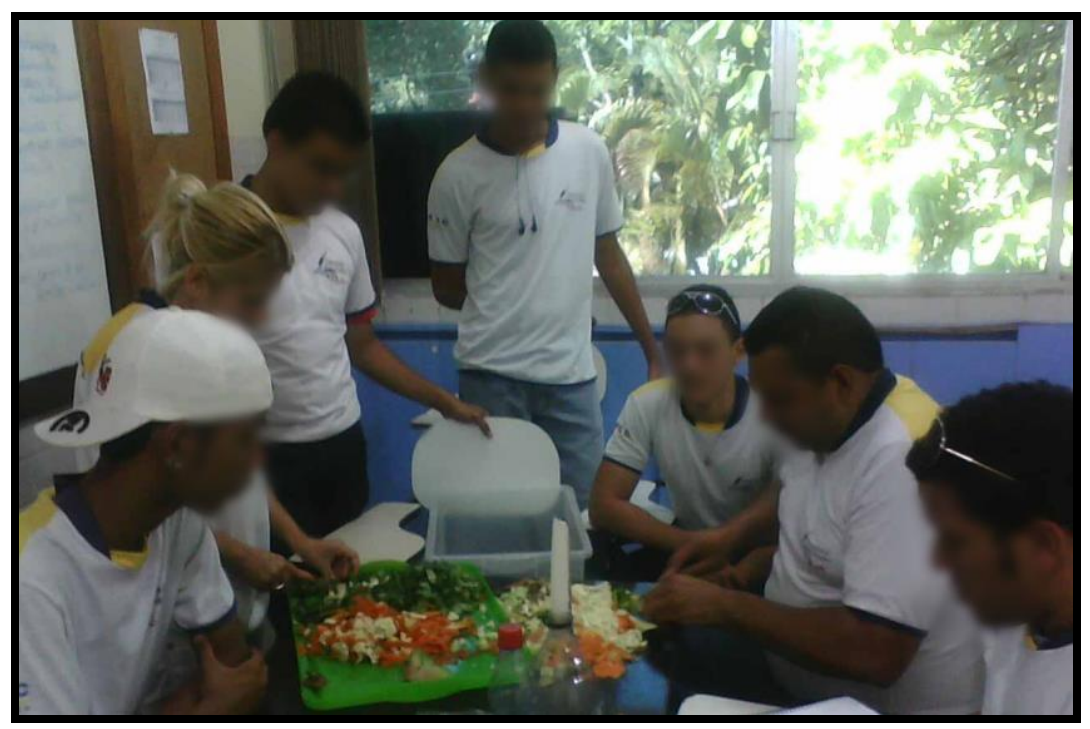

Figura 6: Aula prática: produção de húmus a partis dos resíduos orgânicos descartados. 


\section{Educação Ambiental como meio integrador das atividades realizadas: aliando conceitos teóricos e ações}

Contamos também com a parceria da Biblioteca Gilberto Freyre, que faz parte desta Unidade do SESC, e que tem proporcionado grandes contribuições, no que diz respeito à transmissão de conhecimentos para formação de cidadãos ecologicamente responsáveis. Nela se encontra um espaço reservado, onde é oferecido material para pesquisas e um orientador na área de Educação Ambiental, para atender às necessidades dos alunos, funcionários e usuários, no que diz respeito às práticas ambientalmente corretas.

A importância dessa parceria fundamenta-se na perspectiva de promover informações necessárias que solidifiquem o conhecimento na área de Educação Ambiental. Os referidos saberes irão auxiliar o cidadão em formação a assumir uma postura mais crítica e firme em relação aos cuidados com a natureza.

Sabemos que o processo da aprendizagem se dá diante da união do que $o$ aluno sabe com os novos conhecimentos adquiridos. Reformular questões corriqueiras com conceitos já pré-estabelecidos é algo que requer, no mínimo, desapego e boa vontade para descobrir novos saberes. Aprender novamente é encontrar um sentido especial no que antes não havia (um buscar sentido no que antes não era para ter sentido especial) e, só depois que o olhar se modifica, percebemos o poder de fazer a diferença em atitudes simples, consideradas pequenas.

Como de costume, a biblioteca Gilberto Freyre realiza mensalmente atividades de ações culturais, e, dentre essas atividades, a semente verde foi implantada e as ações foram mudando e renovando o seu sentido. Datas tradicionais de ações como Carnaval e Festas Juninas, voltaram-se para tratar de reciclagem de resíduos sólidos e problemas relacionados com a seca e as queimadas. $O$ que antes só era abordado em sala de aula, pelos conceitos festivos, hoje são abordados também como problemas sociais e ambientais.

No Carnaval, além da parte cultural, inserimos atividades como a de coleta seletiva, com o recolhimento das latinhas de refrigerante em parceria com os catadores de resíduos recicláveis do entorno. Nas festividades juninas também, além da abordagem cultural, passamos a oferecer um momento de debates sobre as práticas de uso de balões, a queima de fogueiras e as suas consequências negativas para o meio ambiente. Dia da Árvore, Semana do Meio Ambiente e dia do Rio são datas que passaram a ter significados. Histórias ambientais voltadas para as temáticas foram pesquisadas e adaptadas para realizar o encontro com as crianças (Figura 7). 


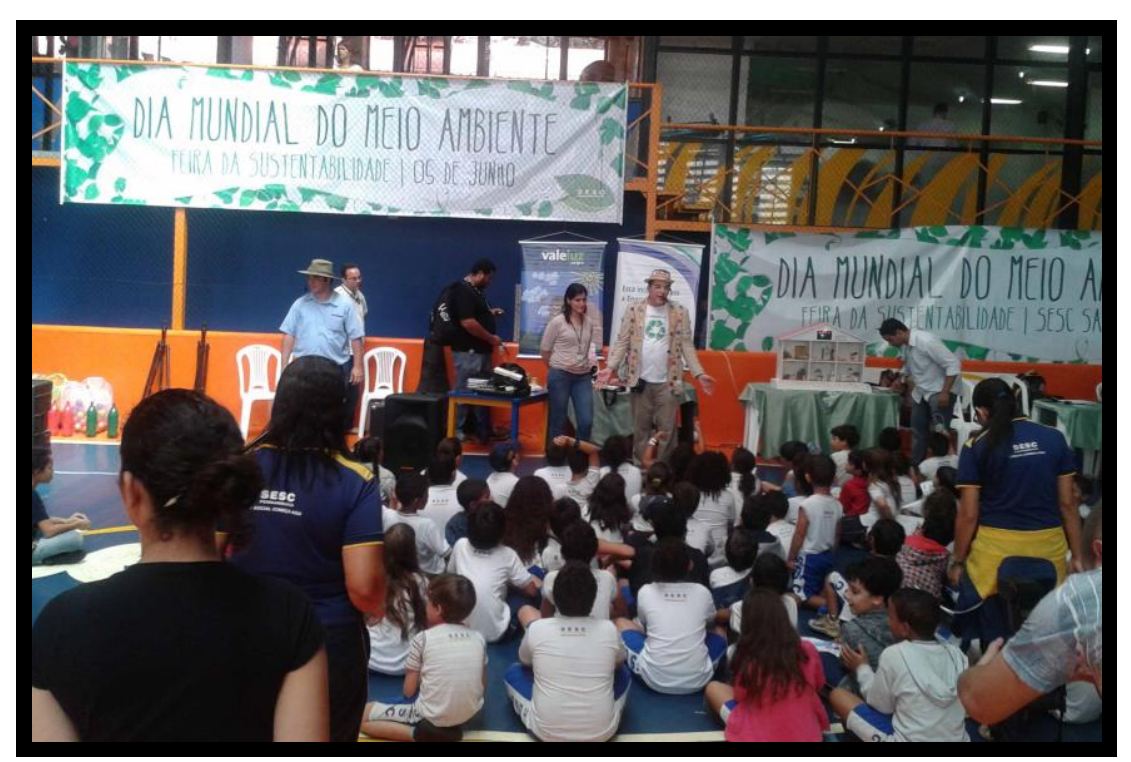

Figura 7: Dia do Meio Ambiente: contação de histórias para as crianças.

Pensar no meio ambiente, realizar ações que, de fato, ofereçam um impacto positivo ao planeta, requer parcerias. O trabalho de vários, imbuídos no ideal de transformar uma realidade, se fortalece quando os resultados são interferências simples que comprovam o sucesso da ação. A participação das ações da biblioteca Gilberto Freyre tem contribuído para a formação de cidadãos conscientes, participativos e prontos para atuar nas comunidades em que vivem.

Este projeto, fruto de um intenso trabalho coletivo, vem se ampliando gradativamente na Unidade Executiva do SESC Santo Amaro, servindo de exemplo para outras unidades de SESC - PE, e contribuindo também em seu entorno para formação de novas frentes de trabalho em Economia Solidária, gerando emprego e renda para a comunidade.

O reconhecimento deste projeto vem se destacando através de prêmios de grande relevância, como a $3^{\mathrm{a}}$ colocação no "Prêmio Construindo a Nação" pelo Instituto Cidadania Brasil patrocinado pelo SESI e o Instituto Evaldo Loide, logo no $1^{\circ}$ ano de implementação (2009) e a 1a colocação neste mesmo prêmio em 2010 na modalidade EJA.

A Lei Nacional dos Resíduos Sólidos de oㅜ 13.205/10, em seu capítulo II Art. 6o - IV; Dos Princípios e Objetivos, no que diz respeito ao Desenvolvimento Sustentável, enfatiza o "reconhecimento do resíduo sólido reutilizável e reciclável como um bem econômico e de valor social, gerador de trabalho e renda e promotor de cidadania" (BRASIL, 2010). Assim, a coleta seletiva, com seu poder transformador socioambiental, apoiada no tripé da sustentabilidade (sociedade, economia e meio ambiente), vem contribuindo para a qualidade de vida desta e das futuras gerações. 


\section{Conclusões}

Esse projeto, que surgiu com um questionamento em sala de aula sobre o descarte correto dos resíduos sólidos, ganhou proporções de fato inesperadas. Temos consciência que sementes foram lançadas, e o tempo se encarregará de transforma-las em bons frutos, em um solo em constante processo de adubação. Trabalhar com mudança de comportamento não é fácil, por isso mesmo temos a consciência de que ainda teremos um bom tempo pela frente para conseguirmos a perfeição. Mas precisamos insistir, para que os cidadãos entendam que, o que para uns é lixo, para outros representa a solução de problemas sociais, além de ser também a solução para os problemas ambientais.

A quantidade de resíduos que são descartados diariamente, de forma irregular, vem causando uma série de impactos ao meio ambiente no que diz respeito à poluição e ao esgotamento dos recursos naturais. Por outro lado, temos uma quantidade enorme de pessoas, que vivem a margem da sociedade, que poderiam melhorar de vida administrando estes resíduos se os mesmos ao invés de irem saturar os aterros sanitários fossem encaminhados para as cooperativas ou grupos de catadores.

A nossa intenção deste trabalho, é de disseminar as sementes, através da Educação Ambiental, formando multiplicadores, para um desenvolvimento que seja economicamente viável, socialmente justo e ambientalmente em consonância com o conceito do desenvolvimento sustentável. Esperamos que nossa experiência tenha cooperado para que outros projetos possam nela se fundamentar e contribuir para melhorar a qualidade de vida na nossa cidade, no nosso país e em nosso planeta. Entendemos que o caminho para a solução de grandes ou pequenos problemas começa com cada um fazendo a sua parte. E parafraseando o grande líder indiano 'Mahatma' Gandhi, concluímos com essa reflexão: "sejamos a mudança que queremos ver no mundo".

\section{Agradecimentos}

Agradecemos aos alunos da EJA do SESC Santo Amaro do ano de 2009 que participaram na idealização e realização deste projeto e aos demais que deram continuidade ao mesmo, a todos os funcionários do SESC Santo Amaro que participaram das ações desse projeto, em especial ao coordenador da EJA, Francisco Lira, ao gerente, Ricardo Melo, a Claudomir Santana e a Rosângela Medeiros, e aos moradores da comunidade do entorno do SESC Santo Amaro que tornaram esse projeto possível. 


\section{Referências}

BOFF, L. Sustentabilidade - O que é - O que não é. Petrópolis, Vozes, 2013 BRASIL, Lei $n^{\circ} 12.305$, de 02 de agosto de 2010. Diário Oficial da União, Brasília, 2010

CASCINO, F. Educação Ambiental: princípios, história, formação de professores. São Paulo, Senac, 1999.

DIAS, R. Gestão Ambiental: responsabilidade social e sustentabilidade. São Paulo, Atlas, 2009.

GRIPPI, S. Lixo, reciclagem e sua história: guia para as prefeituras brasileiras. Rio de Janeiro, Interciência, 2006.

MORAES, R; MANCUSO R. Educação em Ciências: produção de currículos e formação de professores. Ijuí, Unijuí, 2004

PEDRINI, A. Educação Ambiental: reflexões e práticas contemporâneas. Petrópolis, Vozes, 2008.

PENTEADO, H.D. Meio Ambiente e formação de professores. São Paulo, Cortez, 2000. 